\title{
ДЕМОГРАФИЧЕСКАЯ ПОЛИТИКА И ПРАВОВАЯ ПОЛИТИКА: ВОПРОСЫ ТЕОРИИ
}

\section{DEMOGRAPHIC POLICY AND LEGAL POLICY: QUESTIONS OF THEORY}

Yu. Lukin

Summary. The article is devoted to the theoretical issues of defining the concepts of demographic policy, legal policy. In addition, an attempt is made to disclose the issue of the existence of demographic legal policy and its components.

Keywords: demographic policy, legal policy, demographic legal policy.

\author{
Лукин Юрий Михайлович \\ Старший преподаватель, Казанский Федеральный \\ Университет; Председатель, коллегия адвокатов \\ «Закон и Факты» Республики Татарстан, \\ yu.m.lukin@gmail.com
}

Аннотация. Статья посвящена теоретическим вопросам определения понятий демографическая политика, правовая политика. Кроме того, дается попытка раскрытия вопроса существования демографической правовой политики и ее составляющих.

Ключевые слова: демографическая политика, правовая политика, демографическая правовая политика.

«право» и «политика». Связь права и политики проявляется в том, что политика является направляющим компонентом для права. Д.А. Керимов отмечал, что действие права происходит через правовые принципы, правовую политику, правосознание, правоотношения, законность; «право - это отнюдь не только совокупность правовых норм, но и система правовых принципов, правовая политика, а также множество ненормативных установлений» [5, с. 343-347].

Правовая политика, как системная деятельность по оптимизации юридического ресурса, представляет собой набор мер и действий, которые должны отвечать вызовам юридической жизни общества. Правовая политика призвана управлять процессами правового развития конкретной страны, повышать уровень упорядоченности и организации юридического бытия. Правовая политика необходима для формирования полноценной и эффективной правовой системы страны и находить своё преимущественное выражение в нормативно-правовых актах.

Под содержанием правовой политики понимается совокупность свойств и элементов, в которых непосредственно выражаются её сущность и социальная направленность. В широком социологическом плане содержание правовой политики представлено системой отношений, возникающих между различными субъектами политики по поводу государственного признания и официального обеспечения тех или иных социальных интересов в качестве юридических значимых.

Безусловно, представление о правовой политике как особой государственно-правовой стратегии яв- 
ляется наиболее устоявшейся правовой дефиницией, при этом при определении правовой политики и ее классификации в юридической литературе встречаются и иные термины, такие как «стратегия государства в правовой сфере», «государственно-правовая стратегия», «стратегия государственно-правового развития» и даже такие как «направление», «стратегическая линия», «программа», «система идей и установок» [6, с. 197]. На наш взгляд проводить различия между данными терминами не является необходимым, так как они по своей сути объединяют одни и те же элементы правовой и политической системы государства. В этой связи хотелось бы представить точку зрения Н.И. Матузова, отмечавшего, что «правом так или иначе оформляются, закрепляются все виды государственной политики, но правовая имеет свои особенности и свое содержание, она отражает и определяет вектор правового развития страны» [2, с. 35-36].

Определяя правовую политику, можно выделить следующие существенные признаки:

Во-первых, правовая политика представляет собой особое направление проявления государственной политики, в связи с этим основные направления правовой политики задаются общим политическим курсом государства и системой общенациональных приоритетов.

Во-вторых, правовая политика является проводником управления обществом по средством функционирования, использования, организацией и развития права и других правовых явлений.

B-третьих, содержание правовой политики охватывает не все стороны государственно-правового регулирования общественных отношений, а лишь ключевые, главные, отражающие стержневые направления деятельности государства в правовой сфере на том или ином этапе его исторического развития [6, с. 200].

Правовая политика должна обладать стратегией и тактикой, так как прежде всего правовая политика - это деятельность по осуществлению стратегических целей и тактических задач. Цели и задачи связаны со множеством факторов различного порядка, уровня. Правовая политика проводится прежде всего, государственными органами, и в силу этого обстоятельства особое значение имеют принципы, установки, ориентиры правящей деятельности [4, с. 39].

Общественные отношения представляют собой сложное и многогранное явление, когда установить с наибольшей вероятностью как они между собой пересекаются и выявить все взаимовлияния достаточно сложно. Тем более, когда мы говорим о такой сфере, как демография. Не представляется возможным учесть все факторы, которые могут влиять на демографическое поведение в полном объёме. В каждом конкретном случае в отношениях конкретной пары толчком, который может заставить принять решение о рождении ребенка либо отказе от акта рождения, могут стать абсолютно любые явления общественной жизни, которые даже не имеют связи с демографическим поведением.

В общественной жизни вряд ли существуют такие явления и процессы, которые так или иначе не оказывали бы влияния на демографическую ситуацию [7, с. 232]. В праве также трудно назвать какую-либо отрасль, какое-либо законодательство, которые бы не имели отношения к демографическим процессам. В этой связи выделение демографической политики из общей социально-экономической политики государства несколько условно, но необходимо для чёткого определения её направленности, основных принципов обеспечения, для оценки степени её эффективности и активности [8, c. 24].

Демографическая политика - это целенаправленная деятельность государственных органов и иных социальных институтов в сфере регулирования процессов воспроизводства населения. В контекстах, связанных с деятельностью в области народонаселения, используются и другие понятия: социально-демографическая политика, политика народонаселения, семейная политика, планирование семьи, планирование населения, контроль и регулирование рождаемости, контроль населения, управление демографическими процессами.

Демографические процессы и явления при всём своём единстве характеризуются разной степенью изученности и, следовательно, разной степенью познания управляемых ими закономерностей. Закономерность, управляющая тем или иным общественным процессом в области народонаселения, проявляется во вне множеством факторов, которые, как правило, относятся к самым разным сферам жизни - экономическому, нравственному, социально-психологическому, психофизиологическому [9, с. 38].

Демографическая политика должна соответствовать тем целям, которые определяются, исходя из типа воспроизводства, социально-экономического состояния общества и уровня демократизации общества. И, безусловно, осуществление правового воздействия на демографические процессы прежде всего нацелено на получение результата - изменение качественных и количественных показателей в демографических процессах, но при этом оно направлено на будущие поколения, и о её результатах и выполне- 
нии целей можно будет судить далеко не сразу, а лишь когда возможно будет достаточно чётко определить закономерности нового демографического поведения граждан. Учитывая определённую инертность демографических процессов, демографическая политика должна быть долгосрочной, что предполагает сравнительную стабильность правового регулирования и правового воздействия на демографические отношения и процессы.

Наиболее близкий к демографической политике по значению термин - политика народонаселения,используется в узком смысле в качестве синонима, а в широком - кроме регулирования демографических процессов, затрагивает и другие сферы: регулирование условий занятости и труда, а также уровня жизни (доходы, образование, охрана здоровья, социальное обеспечение).

Примером расширенной трактовки политики в области народонаселения может служить точка зрения профессора Юде, представленная в его выступлении в 1919 году в Вене на конференции по охране материнства и младенчества: «Задачей политики населения должно быть создание для всех людей человеческих условий существования, хотя бы в рамках прожиточного минимума» [10, с. 524].

Примером узкой трактовки демографической политики выступает позиция американских социологов Дж. Спенглера и О. Дункана, изложенная в работе «Теория и практика населения» (1956), определяющие её как «конкретный ряд стоящих перед правительством целей, касающихся численности населения и/или состава населения вместо со средствами, с помощью которых можно достичь этих целей» [11, с. 78].

В англо- и испаноязычной научной литературе, в международных документах, рекомендациях и аналитических докладах ООН в основном используется термин «политика населения» (population policy). Tepмин «контроль рождаемости» или «регулирование рождаемости» используют для описания воздействия государства на процесс рождаемости главным образом с целью снижения её уровня и сокращения темпов роста населения в стране. Иногда он употребляется для обозначения контроля рождений (деторождений) на уровне семьи, применения супружескими парами (или индивидуально) методов, с помощью которых они регулируют количество детей в семье.

Регулирование рождаемости путем проведения государственных программ планирования семьи или поощрения деторождения иногда обозначается термином «контроль населения». В этом случае к регулирова- нию рождаемости может добавляться регулирование брачности, стимулирование или ограничение создания брачных пар, например, через возраст вступления в брак.

По определению Б.Ц. Урланиса, демографическая политика представляет собой совокупность социальных, экономических и юридических мер и мероприятий по оказанию определённого влияния на течение демографических процессов в желательном для общества направлении [12, с. 24]. Проведение собственной демографической политики является так же признаком суверенитета каждого государства, так как без таковой невозможно представить экономический суверенитет государства. Наличие собственных трудовых ресурсов прежде всего позволяет государству вообще ставить перед собой какие-либо задачи в сфере экономического развития.

Демографическая политика представляет собой систему мер, направленных на получение определённых демографических результатов, достижение определённых демографических целей. Демографические цели могут существовать для общества либо как непосредственно конечные цели, либо как промежуточные, как средство для решения каких-то более общих задач. В данном случае общество стремится к обеспечению определённых демографических показателей, представляющих для него самостоятельную ценность. Однако в большинстве случаев общество не ставит себе демографические цели в качестве главных, хотя многие цели в социальной и экономической сферах могут быть решены путём правильной постановки целей в демографической сфере.

Демографическая политика не может быть единой для всех государств. В странах с низкой и недостаточной рождаемостью она направлена на повышение или стабилизацию естественного прироста населения, в странах высокой рождаемостью - на её стабилизацию или снижение. Правительство каждой страны суверенно в своих правах определять направление и цели демографической политики государства, учитывая, однако, международно-правовые акты, имеющие прямое или косвенное отношение к демографическим процессам, в частности Всеобщую Декларацию прав человека, Международный Пакт об экономических, социальных и культурных правах, Международный Пакт о гражданских и политических правах, Декларацию прав ребенка и др. [8, с. 22] «Ни один экономический или социальный вопрос в истории Объединенных Наций и её специальных комитетов не сопровождался большими дискуссиями, чем вопрос народонаселения»,- говорится в работе, посвященной деятельности $\mathrm{OOH}$ по разрешению проблем народонаселения [13, с. 1]. 
Определение соотношения правовой политики и демографической политики позволяет ответить на вопрос о формах реализации функций государства и права в сфере демографии.

Демографическая политика и правовая политики представляют собой связанные между собой явления, поскольку часть демографической политики осуществляется путём реализации демографической правовой политики, то есть деятельность государственных органов и иных социальных институтов в сфере регулирования процессов воспроизводства населения происходит через использование правовых норм и, следовательно, правового регулирования как способа достижения поставленных целей в рамках общей демографической политики.

Правовая политика и демографическая правовая политика соотносятся как целое и часть. Демографическая правовая политика - это политико-правовая деятельность, осуществляемая правовыми методами в сфере демографии. Субъектами демографической правовой политики являются государственные и муниципальные органы, общественные объединения граждан, обеспечивающих создание и исполнение системы мер, направленных на получение определённых демографических результатов, достижение определённых демографических целей, определяемых исходя из демографической ситуации в государстве.

В юридической литературе отдельными авторами в системе функций современных государств выделяется демографическая функция [14]. В связи с чем актуализируется вопрос о соотношении демографической правовой политики и демографической функции государства. Следует отметить, что существующие ответы можно разделить на две группы: отдельными авторами отмечается возможность признания за некоторыми направлениями правовой политики значения самостоятельных функций государства; в других работах анализируемые понятия фактически отождествляют.

В рамках поставленного вопроса о соотношении демографической правовой политики и демографической функции государства, представляется необходимым определить соотношении демографической правовой политики и демографической функции права. В одной из немногих работ, посвященных демографической функции права, дается следующее определение: демографическая функция права - это относительно обособленное, прогрессивное направление гомогенного (однородного) юридического воздействия на сознание, волю и поведение людей, способное обеспечить оптимальную численность населения, установить такой режим его воспроизводства, который бы полностью отвечал задачам государства и общества [14].

Безусловно, понятия демографическая правовая политика и демографическая функция права являются соотносимыми, неразрывно взаимосвязанными, но не тождественными. На наш взгляд, отождествление данных понятий не является возможным, так как под функциями права понимаются основные направления правового регулирования, но при этом функция права обусловлена основными направлениями деятельности государства, и даже нередко выступает отдельной правовой функцией государства, в то время как правовая политика может рассматриваться как правовая форма его деятельности.

Демографическая правовая политика определяет общую стратегию деятельности государства в сфере правового регулирования демографических отношений, при этом она призвана вносить необходимые коррективы с учетом изменяющихся задач общества и государства.

Таким образом, можно сделать следующие выводы:

1. Содержание правовой политики охватывает не все стороны государственно-правового регулирования общественных отношений, а лишь ключевые, главные, отражающие стержневые направления деятельности государства в правовой сфере на том или ином этапе его исторического развития. Выделение демографической правовой политики в качестве самостоятельного направления государственной правовой политики определено актуальностью демографической ситуации для Российского государства, что нашло отражение и в одном из одноименных Национальных проектов.

2. Правовая политика и демографическая правовая политика соотносятся как целое и часть. Демографическая правовая политика - это политико-правовая деятельность, осуществляемая правовыми методами в сфере демографии, представляющая собой деятельность государственных органов и иных социальных институтов в сфере регулирования процессов воспроизводства населения происходящих через использование правовых норм и, следовательно, правового регулирования как способа достижения поставленных целей в рамках общей демографической политики. Демографическая правовая политика направлена на получение демографических результатов, обусловленных достижением поставленных демографических целей, которые определяются государством с учетом 
демографической ситуации в стране на данном этапе исторического развития.

3. Основными направлениями демографической правовой политики являются:

- формирование демографической политики стимулирования рождаемости;

- формирование политики укрепления института семьи;
- формирование политики сокращения смертности (как материнской и младенческой, так и смерти в трудоспособном возрасте);

- формирование политики сохранения и укрепления здоровья населения, увеличения продолжительности жизни;

ф формирование политики привлечения мигрантов с учетом их социальной адаптации и интеграции.

\section{ЛИТЕРАТУРА}

1. Алексеев С.С. Основы правовой политики в России: Курс лекций // С.С. Алексеев. М., 1995.

2. Российская правовая политики: Курс лекций / Под ред. Н.И. Матузова и А.В. Малько. М.; 2003.

3. Правовая политика: словарь и проект концепции/ под ред. А.В. Малько; — Саратов, Изд-во ГОУ ВП0 «Саратовская государственная академия права», 2010.

4. Рыбаков 0.Ю. Российская правовая политика в сфере защиты прав и свобод личности: вопросы теории [Электронный ресурс]: Дис. ... д-ра юрид. наук: 12.00.01.-М.: РГБ, 2005.

5. Керимов Д.А. Методология права: Предмет, функции, проблемы философии права. М., 2003

6. Рудковский В.А. Правовая политика и осуществление права: теоритико-методологический аспект [Электронный ресурс]: Дис. ... д-ра юрид.наук: 12.00.01. - М.: РГБ 2009.

7. Борисов В.А. Перспективы рождаемости// В.А. Борисова.— М. 1976.

8. Литвинова Г.И. Право и демографические процессы в СССР// Г.И. Литвинова. - Издательство «Наука», 1981

9. Короткова Т.И. Народонаселения и право//Т.И. Короткова — Советское государство и право, 1969 год № 1

10. Экономика народонаселения: учебник/ под ред. Проф. В.А. Ионцева.—М.: ИНФРА-М.— М.,2007

11. Population Theory and Policy /Eds. by J.J. Spengler, 0.D. Duncan. - 1956

12. Урланис Б.Ц. Народонаселение: исследования, публицистика //Б.Ц. Урланис.— М.

13. Symonds R., Carder M. The United Nations and the Population Question (1945-1970)/ Symonds R., Carder M. — N.J. 1973

14. Бадоев М.Т. Демографическая функция права [Электронный ресурс]: Дис. ... канд. юрид. наук: 12.00.01. — М.: РГБ 2004. 